\title{
Enhancing the Early Student Experience
}

\author{
Eileen Trotter, e.trotter@salford.ac.uk
}

\begin{abstract}
This paper is concerned with identifying how the early student experience can be enhanced in order to improve levels of student retention and achievement. The early student experience is the focus of this project as the literature has consistently declared the first year to be the most critical in shaping persistence decisions. Programme managers on courses with good and poor retention rates have been interviewed to identify activities that correlate with good retention rates. The results show that there are similarities in the way programmes with good retention are run, with these features not being prevalent on programmes with poor retention. Recommendations of activities that will enhance the early student experience are provided.
\end{abstract}

\section{Introduction}

This research was conducted on behalf of the Teaching and Learning Development Sub-committee. The author was seconded for one semester in 2002/03 to the Education Development Unit to carry out the research. The aim of the project was to identify activities that enhance the early student experience to enable specific recommendations to be made in relation to the student experience in the first year, in order to improve retention and achievement rates. This paper reports the results of the project. A review of literature on student retention is provided, details of the research method adopted is explained along with the findings and resulting recommendations.

\section{Context and Background}

This paper is concerned with dealing with the effect of a mass higher education system and both government and institutional policy of widening participation. Widening participation means that a greater variety of students is entering higher education, however true participation is only achieved when these students are enabled to do justice to their recognised potential and attain their qualifications.

It is necessary to recognise that a possible reason for a student withdrawing rests within the university and can therefore be addressed. While Floud (2003) argues that performance indicators show that most of the variation in non-completion rates can be explained, at least in statistical terms, by variation in the characteristics of student recruits, the Secretary of State for Education and Employment (2000) stated, "there are unacceptable variations in the rate of 'drop out' which appear to be linked more to the culture and workings of the institution than to the background or nature of the students recruited.”

\section{Issues that Impact on Retention}

\section{Pre-entry Information}

Kealy and Rockel (1987) investigated student perceptions of college quality and found that first impressions measured through the campus visit were a very strong influence across all dimensions of college quality. Students with a positive first impression of a university may be extrinsically motivated to persist and vice versa (Allen, 1999). 
Yorke and Thomas (2003) found that institutions that performed higher than their HEFCE benchmarks for completion were involved in outreach work with potential entrants. Providing the student with information between application and enrolment can also assist the development of the student/institution relationship.

\section{Induction}

Students' decisions to withdraw are significantly affected by the degree of their intellectual and social integration into the life of the institution (Johnson, 1994; Tinto, 1982). It is possible to lessen considerably the social trauma of moving from the relatively secure social environment of school and college to that of an unknown and possibly distant university environment (Tinto, 1982).

The needs of clearing students must also be considered: Bennett (2003) discovered that those students who began their academic career late and missed the first few weeks of semester were more likely to feel lonely and isolated and be generally dissatisfied with the programme.

\section{Personal Tutor Support}

The transformation from an elite towards a mass higher education system in the UK has brought with it a much wider diversity of students into our institutions who might previously have been prevented from participating and who are more likely to need additional support. Yorke and Thomas (2003) found that one institution in their study had developed much tighter guidelines for students and staff about the purpose and contents of tutorials and another had introduced a more proactive variant in which the tutorial was based around an agenda that had to be prepared in advance by the student.

In a study by Gutteridge (2001), every single student interviewed reported some difficulty when entering higher education and the issue is further complicated by the fact that the time of a young individual's life assigned traditionally to the pursuit of higher education is also a time of intense moods and swings of attitudes (Raaheim et al 1991).

\section{Attendance}

Students who withdraw have been found to miss classes more often, have poorer study skills and less efficient time management skills than students who continue with their studies (Fitzgibbon and Prior, 2003; Johnson, 1994). Gracia and Jenkins (2002) found that the attendance rate of those students who passed their course ranged from $67 \%$ - $98 \%$ with an average attendance rate of $88 \%$ while attendance of those who failed ranged from $53 \%-92 \%$ with an average rate of $69 \%$.

\section{Teaching and Learning Activities}

Instructor behaviour has been associated with differential student persistence (Johnson, 1994). Heywood (2000) argues that the effective delivery of the curriculum depends on multiple-strategy approaches to instruction. The requirement is for methods stressing active learning rather than the traditional lecture (Biggs, 1999). Thomas (2002) concludes that characteristics identified by students as impacting on persistence decisions include collaborative teaching and learning which promotes social relations between students through academic activities.

Other previous research on retention has focussed on reasons why students withdraw or what characteristics students who do not complete their programme of study may have. A theory of possible actions that, as a result, may encourage students to persist has 
developed. These theories have been developed by analysing statistics obtained from questioning students on their background and reasons for withdrawal. While Martinez (1997) supports the idea that retention rates could be improved by institution based initiatives, a review of student non-completion models undertaken by Laing and Robinson (2003) indicates that current models offer little in the way of explanations of the causes of non-completion or little justification for the strategies used to reduce non-completion. There is very little in the way of guidance on or hard evidence of which strategies are likely to stimulate the greatest improvements (Johnston, 2001).

This study looks at what actually happens within an institution and seeks to relate that to its effect on the early student experience with particular reference to student achievement and retention. It focusses on activities operating within programmes rather than the characteristics and opinions of students.

\section{Research Method}

The over-riding research question is: in what ways might programmes be run to make them more effective at optimising student achievement and retention? The research focusses on the institution and particularly on the way that courses are managed. It considers if there are activities inherent on programmes with good student retention and achievement that do not feature as strongly or are not present in those programmes with poor student retention and achievement. The results of the research, while perhaps not providing hard evidence of causality, instead provide evidence that there is a correlation between activities that are a common feature in certain programmes and good retention rates.

There were three elements to the research: to identify programmes with good and poor retention, to explore the key issues that influence retention, and to discover if there are activities common on programmes with good retention that are not prevalent on programmes with poor retention.

Programmes were selected by triangulating information from internally generated statistics prepared by the University management, annual programme reviews prepared by programme managers, HEFCE (2002) statistics and suggestions from heads of school or other relevant people who were aware of problems or good practice. Programmes were selected from all schools within the University and twenty programme managers were asked to participate. Sixteen programme managers responded and interviews were conducted representing fifteen programmes in fourteen out of sixteen schools. Six of those interviewed represented programmes with good retention rates (Group A) and nine represented programmes with poor retention rates (Group B).

Programmes were selected to ensure that a variety of pre-entry qualifications and student numbers were represented in both groups. Some programmes within both groups accepted students through clearing. Programmes were then categorised into discipline type as recognised in the literature (see Neumann et al, 2002) to ensure that particular discipline types were not more prevalent in one group. There was a variety of discipline type within each group. In this way it was ensured that the student profile, the number of students on a programme or discipline type would not influence the results.

The second element of the research involved the identification of key issues that affect student achievement and progression in the first year at university. These issues were identified from a number of sources. A review of literature on student retention and achievement was conducted. Focus groups were held at a University management retreat 
where groups were asked to consider issues surrounding student retention. A workshop on student retention was attended and copies of the poster displays resulting from the discussions in this workshop were obtained. Insight into current debate and research on retention was obtained from attendance at and participation in a national conference on student retention. These various sources allowed identification of issues that may impact on student retention. From this list of possible influences on retention, six broad areas were identified to provide a focus for the research.

The third stage was to conduct semi-structured interviews with programme managers, to allow access to their accounts and articulations of activities within their programme. An interview guide was prepared around each of the six broad areas previously identified and further issues as pointers were included to ensure that interviewees discussed the topics that were considered important.

Data were analysed by personally transcribing interviews and reading and re-reading transcripts in order to be familiar with the content, assigning codes to portions of the data, identifying emerging themes and generating results based on these themes.

\section{Results}

The results below highlight areas where there are differences between programmes with good retention rates and those with poor retention rates. Participants were assured of anonymity and so any identifying features have been removed.

\section{Pre- entry Information}

- The information provided to prospective students in Group A is more comprehensive than that in Group B and is targeted to reach the appropriate audience.

Programme managers in Group A were more involved in recruitment and admissions while those in Group B did not see it so much as their responsibility.

Right, it's not really my area, it should be, I know (B8)

All of Group A recognised the importance of the prospectus entry while only two in Group B thought it was important.

Most of the evidence seems to point to the prospectus (A5)

I don't think the students take an awful lot from the brochure to be honest

There was evidence from a participant in both groups that a prospectus entry improved numbers applying to their course which confirms that a prospectus entry is still a main source of information for prospective students.

All Group A had school and college links and four were involved in enrichment days, with the corresponding results for Group B being three and one. All programmes had open days but Group A were much more enthusiastic about their importance, ensuring the format fits the audience and that all students are provided with relevant information

Four programmes in Group B appear to be promoting their course to the wrong market or are unsure how to promote the course. 
The problem is on the outreach programme, he tends to go to better schools from which we don't really draw our students.......it's a good laugh going up to X College but realistically we don't get students from it so it doesn't really help (B5)

The conclusion here is that programmes in Group A work harder to attract students. They are more likely to be involved in HE enrichment days, have more links with local schools and colleges and are more involved in the provision of an appropriate prospectus entry.

\section{Induction}

- A much greater effort is made in Group A to help students to settle in, make friends and get to know other students on their programme.

Both groups provided induction for their students during freshers' week. However the format and focus of the induction sessions differed. All those in Group A actively involved students, with provision to allow students to get to know one another with fun tasks and ice-breakers. None in group B did this with induction sessions in Group B being more didactic.

The focus really of induction week is getting them to know each other (A2)

Every programme in Group A linked part of their induction with what students would be involved in later on in the course. Only one programme in Group B did this. Four programmes in Group A used induction week to get to know the students and to identify and attempt to remedy possible problems students may have, while none in Group B did this.

Those programmes in Group A who accepted clearing students provided late applicants with relevant information to inform their decision and then ensured they were integrated. Two of Group B recognised the problem with late entrants having already missed out on open days and one of these intends to have clearing open days for the first time this year to remedy this problem.

To summarise, induction in Group A was more activity based with the emphasis on keeping the process informal and allowing students the opportunity to meet each other and integrate as a cohort. Group A were more likely to use induction week to recognise possible problems and attempt to remedy them. Students accepted through clearing to programmes in Group A were more likely to be provided with time and additional information to inform their decision, although there was evidence that clearing open days were scheduled for this year.

\section{Personal Tutor Support}

- There is a much stronger tutor support and monitoring system in Group A than Group B.

The type of personal tutor support provided in the two groups was markedly different. In Group A, personal tutorials were linked more strongly with the course with a concerted effort to allocate students to tutors who either taught them or had very close links with the course, whereas in all cases in Group B, personal tutors were allocated completely at random.

Students were seen more regularly and more often in Group A. Those in Group B scheduled meetings only either once or twice each semester. In group A, meetings were timetabled and linked to modules either related to their course or to study skills support, 
whereas in Group B, meetings were arranged by placing a list on the notice board or tutor's door and were less likely to have an agenda.

In Group A, the personal tutor's role was to provide both academic and personal support, in three cases monitoring academic progress and providing counselling on this when required. In only one programme in Group B was personal and academic support linked, with the others lacking a focus for meetings and contact being provided as and when required. Students are more likely to attend personal tutorial meetings in Group A. On one programme, it is a requirement, on three, attendance was considered good and on one, it was patchy. In group B, seven programme managers reported that either students did not attend meetings or that attendance was poor. Only one was satisfied with their attendance.

It's expected- more than it's expected - it's required in order to progress through the programme (A4)

...about in November, so the students will have been here six or seven weeks. Of course with these numbers and pressures, it may be that some of these students are seen in week ten or eleven (B3)

The conclusion is that Group A has more effective and successful personal tutor systems. They are more likely to be timetabled with meetings scheduled regularly and early in the first semester. They are more focussed and directed, fulfil an academic as well as a personal role with personal tutorials being better attended than in Group B.

\section{The Impact of Undertaking Paid Employment and Other Commitments}

- Group A is more likely to provide a "nicer" timetable that facilitates part-time employment and time for other commitments.

Programme managers were asked to comment on what impact students taking on paid employment had on their programme. The main difference between the two groups was that the class timetable of Group A was more likely to provide free days. Both groups indicated that they would be flexible in allowing students to change classes if possible to cater for work or childcare commitments.

I've tried to give all students in every semester on every level, one clear day and another half, so sometimes they get more than that ............It certainly helps student satisfaction in terms of complaints about the timetable. It seems to be one element of overall satisfaction with the programme (A1)

\section{Attendance}

- Group A emphasise the importance of attendance more and are more strict in monitoring attendance.

Five programmes in Group A reported that attendance was strictly monitored in all modules, with one indicating that it was "sort of" monitored. The results for Group B were that on one programme attendance was strictly monitored, two reported they did not monitor attendance, one reported that he monitored it and as a result other module leaders did not need to, and the other five indicated that attendance was either poorly or not strictly monitored. The ethos in Group A was more that attendance was required and not just expected, with students asked to provide an explanation for non attendance. 
We tell them right from the beginning how important it is......I chase them up and colleagues chase them up as well, yes we are quite rigorous (A6)

\section{Teaching and Learning Activities}

- Group A utilised more active teaching and learning techniques, while Group B tended to favour a more didactic model.

All programmes had a variety of teaching and learning methods involving lectures, seminars, tutorials, workshops, group work, presentations and so on. However the response from six in Group B was that the traditional lecture, tutorial was adopted while none in Group A mentioned that format. All six in Group A mentioned involving students more actively in learning while only two in Group B mentioned this. This response was not only from the practical type subjects but also those where the topic could be taught by a traditional lecture or by hands on experience.

\section{Assessment}

- Group A made less use of formative assessment, preferring to grade all work submitted.

This is an interesting result as the literature tends to favour the use of formative assessment as a means of improving learning. There was a variety of forms of assessment including coursework essays and projects both individual and in groups, short tests and examinations. Interestingly, Group A employed formative assessment, in its strict sense of not contributing towards the final mark, less than Group B, with only one on Group A utilising it and three on Group B. Traditionally summative assessment measures student achievement and formative assessment enhances learning (Light and Cox, 2001). However Ramsden (1992) encourages that assessment should be linked to learning by assessing during the experience of learning as well as at the end of it.

\section{Recommendations}

Recommendations of activities that will enhance the early student experience and improve retention are detailed below, organised into suggestions at programme level and at University level.

\section{Programme Level}

\section{Pre-entry}

Be involved in effective and appropriate marketing of the programme including the provision of correct and up to date prospectus entry, web page, leaflets; Have open days, ensuring the target market is informed and invited; Develop links with schools and colleges; Be involved in the higher education enrichment programme; Ensure applicants through clearing are provided with appropriate information and time to inform their decision.

\section{Induction}

Organise induction around activities aimed at helping students to get to know one another; Link part of induction with what students will be involved in later on in the course; Use induction week to get to know the students and to identify and attempt to remedy possible initial problems students may have. 


\section{Personal Tutor Support}

Timetable personal tutor meetings regularly in the first semester reverting to at least once per semester after this; Provide an agenda for personal tutor meetings with an academic link e.g. personal development planning, study skills, review and reflection on assessment results.

\section{The Impact of Undertaking Paid Employment and Other Commitments}

\section{Request a timetable which facilitates part-time employment and time for other commitments.}

\section{Attendance}

Encourage an ethos of attendance being a requirement; Monitor attendance and have procedures for contacting absentees.

\section{Teaching and Learning Activities}

Employ teaching and learning strategies that involve students actively in class.

\section{Assessment}

Restructure assessments to incorporate an element of continuous summative assessment.

\section{University Level}

Expand the higher education enrichment programme to involve all schools within the University; Encourage, co-ordinate and facilitate development of links with local schools and colleges at programme level; Provide staff development workshop on induction with particular emphasis on activities designed to help students integrate; Review the personal tutorial system to consider how best student personal support should be provided. Suggestions include: dedicated member of staff per programme to provide personal tutorial support; member of academic staff in each school to co-ordinate personal tutorial support; Develop an agenda / course of activities that can be followed in personal tutor meetings; Structure timetables so that at least one day free of timetabled classes is provided on all programmes; Provide timetables before the start of semester; Provide staff development workshops on teaching and learning strategies that encourage active learning in (large) classes.

\section{Conclusions}

This research has attempted to answer the question, in what ways might programmes be run to make them more effective at optimising student achievement and retention? It has questioned whether there are activities inherent on programmes with good student retention and achievement that do not feature as strongly or are not present in those programmes with poor student retention and achievement. The results show that there are similarities in the way programmes with good retention are run, with these features not being as prevalent in programmes with poor retention.

Group A programmes were found to operate differently in a number of areas. They were more likely to provide comprehensive pre-entry information to prospective students. Links with schools and colleges were stronger. Group A programmes did not only target prospective students to their programmes but were also more likely to be involved in general higher education information and enrichment days. Induction for new students was more likely to be programmed around activities aimed at helping students to settle in and get to know other students on their programme. It was also more likely to be linked 
with some activities that students would be involved with in their future course. Personal tutorial support was stronger, more likely to be linked to the course academically with meetings more likely to be attended by students and with a more focussed agenda. Group A programmes were more likely to provide a timetable that facilitated part-time employment and students' other commitments. The ethos of attendance on Group A was more likely to be one of requirement rather than encouragement with attendance being more closely monitored. Teaching and learning methods were more likely to encourage students' active involvement in class while Group B programmes favoured more traditional forms of tuition.

The conclusion therefore is that there are differences in the operation of programmes with good and poor retention rates. It is comfortable to see the world as one where students leave for personal or financial reasons and other factors external to the institution, however concurring with Blythman and Orr (2003), there is an institutional contribution to improving retention. While this study does not seek to provide evidence of causality, there is clear correlation between recognised activities and programmes with good retention rates.

If universities are going to take students from a wider range of educational backgrounds, maintain standards, and give students a good chance of succeeding, more resources will be required (Bekhradnia \& Thompson, 2002). This research provides the evidence that it is worthwhile spending time and resources to develop the activities detailed. Widening participation does not need to mean a fall in retention rates. A range of factors has been identified here that in all probability, contribute to improved rates of retention.

\section{Acknowledgements}

I wish to thank the members of the Enhancing the Early Student Experience Steering Group at the University of Salford who gave their time to support this project. Their assistance and guidance throughout its various stages was invaluable and provided the direction necessary to ensure the project fulfilled its aims. Thanks are also given to staff on the Doctoral Programme in Educational Research at Lancaster University who provided feedback and comments on earlier drafts of this paper.

\section{References}

Allen, D. (1999). Desire to finish college. Research in Higher Education 40(4)

Bekhradnia, B. \& Thompson, J. (2002) Reflection of Success. Guardian Education, 15 October

Bennett, R. (2003) Determinants of Undergraduate Student Drop Out Rates in a University Business Studies Department. Journal of Further and Higher Education, 27(2)

Biggs, J. (1999) Teaching for Quality Learning at University. Buckingham: SRHE and OUP

Blythman, M. and Orr. S. (2003) A Joined-up Policy Approach to Student Support in Peelo, M. and Wareham, T. (eds) Failing Students in Higher Education. Buckingham: Open University Press/SRHE

Brown, G., Bull, J., Pendlebury, M. (1997), Assessing Student Learning In Higher Education, London: Routledge

Earwaker, J. (1992) Helping and Supporting Students Buckingham: SHRE and OUP 
Fitzgibbon, K. and Prior, J. (2003) Student Expectations and University Interventions - a timeline to aid undergraduate student retention. Paper presented at LTSN BEST Conference, 9-11 April

Floud, R. (2003). Policy Implications of Student Non-completion: Government, Funding Councils and Universities in Peelo, M. and Wareham, T. (eds) Failing Students in Higher Education. Buckingham: Open University Press/SRHE

Gracia, L. and Jenkins, E. (2002). An exploration of student failure on an undergraduate accounting programme of study. Accounting Education, 11 (1) 93-107

Gutteridge, R. (2001) Student support, guidance and retention; re-defining additional needs, Paper presented at the Qualitative Evidence-based Practice Conference, Taking a Critical Stance. Coventry University, May 14-16

HEFCE (2002) http://www.hefce.ac.uk/Learning/perfind/2002/

Heywood, J. (2000) Assessment in HE: student learning, teaching, programmes and institutions London: Jessica Kingsley

Johnson, G. M. (1994) Undergraduate Student Attrition: A Comparison of the Characteristics of Students Who Withdraw and Students Who Persist. The Alberta Journal of Educational Research XL(3) 337-353

Johnston, V. (2001) Developing Strategies to Improve Student Retention: Reflections from the Work of Napier University's Student Retention Project. Conference paper presented at SRHE, December. Available online at http://www.napier.ac.uk/qes/studentretentionproject/Documents/SRHE\%202001\%20Ca mbridge.doc

Kealy, M. J. and Rockel, M. L. (1987). Student perceptions of college quality: the influence of college recruitment policies. The Journal of Higher Education 58: 683-703, cited in Allen, (1999)

Laing, C. Robinson, A. (2003). The Withdrawal of Non-traditional Students: developing an explanatory model. Journal of Further and Higher Education, 27(2)

Light, G. and Cox, R. (2001) Learning and Teaching in Higher Education, London: PCP Publishing

Neumann, R., Parry, S., Becher, T. (2002) Teaching and Learning in their Disciplinary contexts: a conceptual analysis, Studies in Higher Education, 27:4

Raaheim, K., Wankowski, J., Radford, J. (1991) Helping Students to Learn, Teaching, Counselling, Research Buckingham: SHRE and OUP

Ramsden, P. (1992), Learning to Teach in Higher Education, London: Routledge

Secretary of State for Education and Employment (2000). Funding Letter to the Higher Education Funding Council for England, 29 November, cited in Parry (2003) and Floud (2003)

Thomas, L. (2002). Student retention in higher education: the role of institutional habitus. Journal of Education Policy, 17 (4) 423-442

Tinto, V. (1982). Limits of Theory and Practice in Student Attrition. The Journal of Higher Education, 53 (6) 687-700 
Education in a Changing Environment $13^{\text {th }}-14^{\text {th }}$ September 2004

Conference Proceedings

Yorke, M. and Thomas, L. (2003) Improving the Retention of Students from Lower Socio-economic Groups. Journal of Higher Education Policy and Management, 25(1) 